\title{
Technical note: A simplified PCR-based assay for the characterization of two prolactin variants that affect milk traits in sheep breeds
}

\author{
M. Orford, O. Tzamaloukas, C. Papachristoforou, and D. Miltiadou ${ }^{1}$ \\ Department of Agricultural Sciences, Biotechnology and Food Science, Cyprus University of Technology, 3603 Lemesos, Cyprus
}

\begin{abstract}
In the present study, a rapid and cost-effective PCRbased assay was developed for the genetic identification of 2 different variants within intron 2 of the prolactin gene. This polymorphism has previously been associated with milk traits in some ovine breeds and was recently proposed as a potential marker for future breeding schemes in dairy sheep. Until now, 2 alleles (A and $\mathrm{B}$ ) have been identified by PCR-RFLP that included HaeIII digestion of a 2.5-kb PCR fragment. By partial sequencing of the prolactin gene intron 2 , it was found that the $\mathrm{B}$ variant results from a 23-bp deletion of the $\mathrm{A}$ variant of the prolactin gene and not from an extra HaeIII digestion site, as had been reported. This finding assisted the design of new primers for analysis of prolactin intron 2 variants based on the size of an easily amplified short PCR product, thereby avoiding the need and cost for additional digestions. The method was validated by genotyping 80 animals from 2 breeds and showed $100 \%$ sensitivity and specificity compared with the PCR-RFLP assay. The established simplified PCR assay was then successfully used to genotype 356 Chios sheep.
\end{abstract}

Key words: genotyping, marker assisted selection, polymerase chain reaction-restriction fragment length polymorphism, prolactin

The dairy sheep industry plays a vital commercial role in many Mediterranean countries. Milk is used mainly for the production of high-quality cheese from local dairy breeds; therefore, both milk yield and content are important selection objectives (Carta et al., 2009). However, because of financial and practical restrictions, genome-wide selection is usually unfeasible for most dairy sheep breeds, making the application of selection schemes assisted by molecular information on causal mutations of genes affecting milk traits an attractive alternative in dairy sheep (Carta et al., 2009).

Received June 28, 2010.

Accepted September 6, 2010.

${ }^{1}$ Corresponding author: Despoina.Miltiadou@cut.ac.cy
Prolactin $(\boldsymbol{P R} \boldsymbol{L})$ is a lactogenic hormone that plays a significant role in milk production; its depletion in sheep provokes a severe reduction of milk secretion (Knight, 2001), suggesting that $P R L$ is a functional candidate gene that could contribute to variations in milk yield. In addition, the $P R L$ gene is located in a region of the ovine chromosome 20 where putative QTL for fat percentage (Gutiérrez-Gil et al., 2009) and milk, fat, and protein yield (Barillet et al., 2005) have been proposed. Therefore, $P R L$ also could be used as a positional marker gene associated with milk production and composition traits.

Among the limited polymorphisms that have been identified in the ovine $P R L$ gene, 2 variants (A and B) within intron 2 have been associated with milk-related traits (Ramos et al., 2009; Staiger et al., 2010). The $P R L$ genotypes significantly affected milk yield and fat and protein content in Serra da Estrela sheep (Ramos et al., 2009). More recently, Staiger et al. (2010) suggested that the $P R L$ intron 2 polymorphism significantly affects milk yield in East Friesian sheep and could therefore be used as a potential marker in selection breeding programs.

To date, the 2 variants in the ovine $P R L$ gene have been distinguished based on HaeIII digestions of PCR products, as first described by Vincent and Rothschild (1997), although the precise genetic nature of these forms have until now remained uncharacterized. Because little has been published on the ovine intronic sequence, the original assay relied on the generation and subsequent restriction digestion of a $2.5-\mathrm{kb}$ PCR product from genomic DNA, using primers that anneal in known flanking exonic sequences. However, the generation of such long PCR fragments from genomic DNA is often difficult and requires extra handling (Schwarz et al., 1990; Wilton and Lim, 1996). In addition, the use of restriction enzymes increases the genotyping cost and time to complete the analysis.

In the present study, the development of a simplified, rapid, and cost-effective method of genotyping prolactin intron 2 variants is described. By direct DNA sequencing of $\mathrm{PCR}$ products generated from $\mathrm{AA}$ and $\mathrm{BB}$ homozygous animals, we determined that the $\mathrm{B}$ allele is the result of a 23-bp deletion in the region flanked 


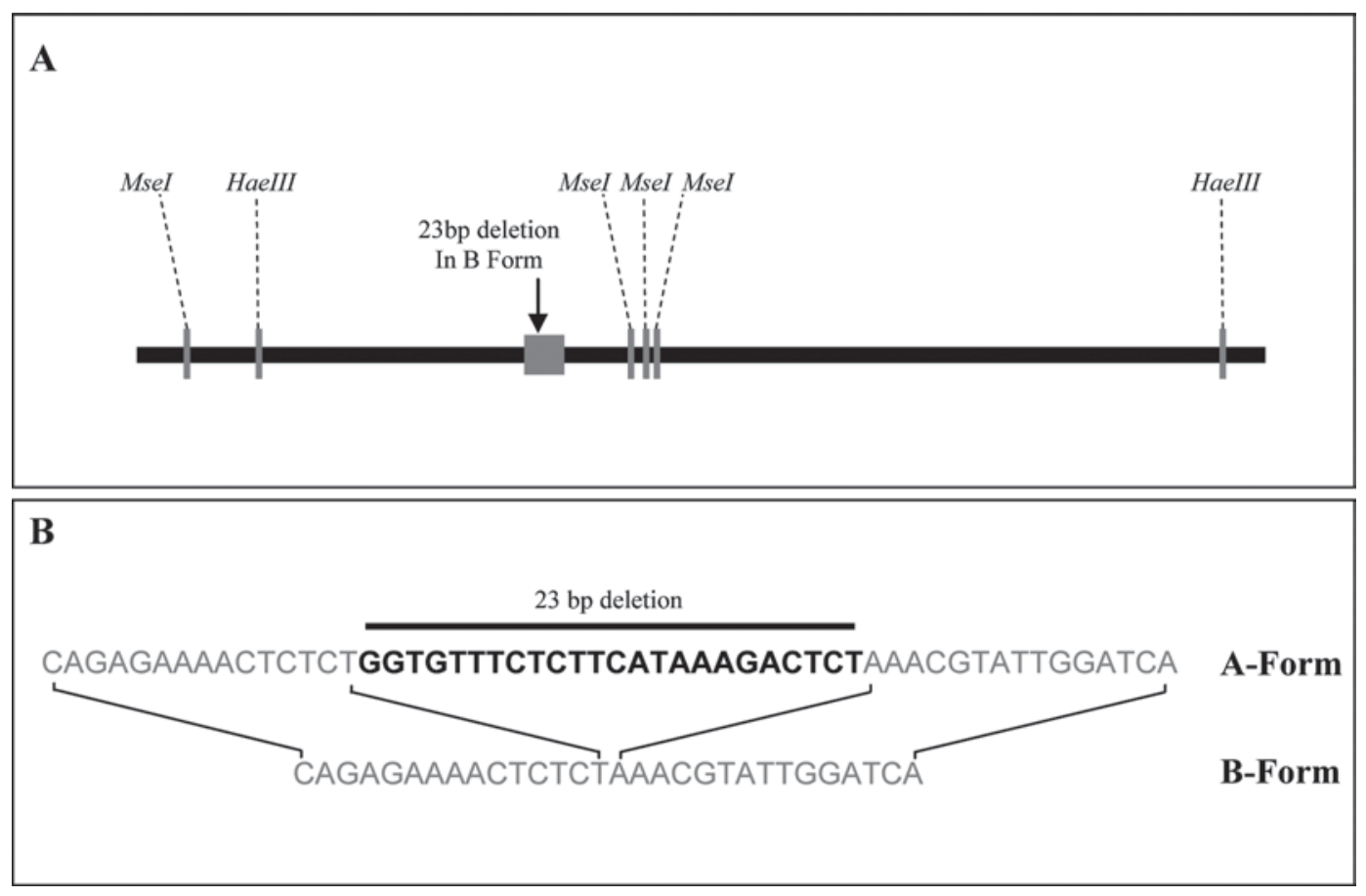

Figure 1. Molecular characterization of ovine prolactin $(P R L)$ variants A and B. (A) Schematic representation of the intron 2 region of the ovine $P R L$ gene harboring the deletion; (B) precise DNA sequence of the deletion within intron 2 of the ovine $P R L$ gene.

by 2 HaeIII sites (Figure 1). This finding facilitated the design of new primers flanking the deletion; therefore, genotyping of the 2 alleles is possible by using a simplified PCR assay, based solely on the size of a short PCR product without the need for digestions (Figure 2).

Genomic DNA was extracted from whole blood samples with a genomic DNA blood kit (MachereyNagel GmbH, Düren, Germany) according to the manufacturer's instructions. Primers PRL-F or PRL-R used for the amplification of the ovine prolactin intron 2 sequence were designed against the bovine prolactin genomic sequence (GenBank accession no. NC 007324), using the online program Primer3 (http://frodo.wi.mit. edu/primer3/input.htm). Amplification of DNA with primers PRL-F or PRL-R from AA and BB homozygous animals, as characterized by a modification of the method described by Vincent and Rothschild (1997), yielded 1,209- and 1,186-bp PCR products, respectively. The DNA sequencing of the agarose gel-purified PCR products was performed from both ends, using either primer PRL-F or PRL-R with the BigDye Terminator v. 3.1 cycle sequencing kit (Applied Biosystems, Carlsbad, CA), and analyzed on an ABI 3130 genetic analyzer. Each obtained sequence was confirmed to be a $P R L$ intron 2 sequence because each exhibited $89 \%$ identity to the bovine counterpart and included HaeIII and $M s e \mathrm{I}$ restriction enzymes sites in locations consistent with the original method of Vincent and Rothschild
(1997; Figure 1). The novel sequences were submitted to GenBank with accession numbers HM234397 and HM234398 for the A and B alleles, respectively.

Based on the obtained intronic sequences, primers PRLDel-F (5'-TCTGCTAAGGGCTCTGCCTA-3') and PRLDel-R (5'-ACAAGGGAAGCCCAGAAGAT- $\left.3^{\prime}\right)$ were designed to flank the deletion. Amplifications were performed in a final volume of $25 \mu \mathrm{L}$ using $10 \mathrm{ng}$ of genomic DNA, $2.5 \mathrm{mM} \mathrm{MgCl}, 0.4 \mu M$ PRLDel-F, $0.4 \mu M$ PRLDel-R, and $1 \mathrm{U}$ of Taq DNA polymerase (Qiagen, Valencia, CA). Following an initial 5-min denaturation step at $94^{\circ} \mathrm{C}$, the $\mathrm{PCR}$ reactions were subject to 30 cycles of $94^{\circ} \mathrm{C}$ for $30 \mathrm{~s}, 56^{\circ} \mathrm{C}$ for $30 \mathrm{~s}, 72^{\circ} \mathrm{C}$ for $30 \mathrm{~s}$, and a final elongation step for $5 \mathrm{~min}$ at $72^{\circ} \mathrm{C}$. Clear, highintensity bands of the expected size (213 bp for the A allele and $190 \mathrm{bp}$ for the B allele) could be resolved on $2 \%$ agarose gels run for $45 \mathrm{~min}$. Allele sizes were compared to a 100-bp DNA ladder (Figure 2).

The sensitivity and specificity of the method was evaluated in a double-blind experiment that included 80 animals from 2 breeds, 40 of which were Chios sheep randomly selected from an experimental farm based at the Agricultural Research Institute (Nicosia, Cyprus) and 40 Cyprus Fat-Tailed sheep provided by a commercial farm in Cyprus raising purebred animals of this rare breed. All animals were genotyped by both the proposed simplified PCR assay and a modification of the method described by Vincent and Rothschild 


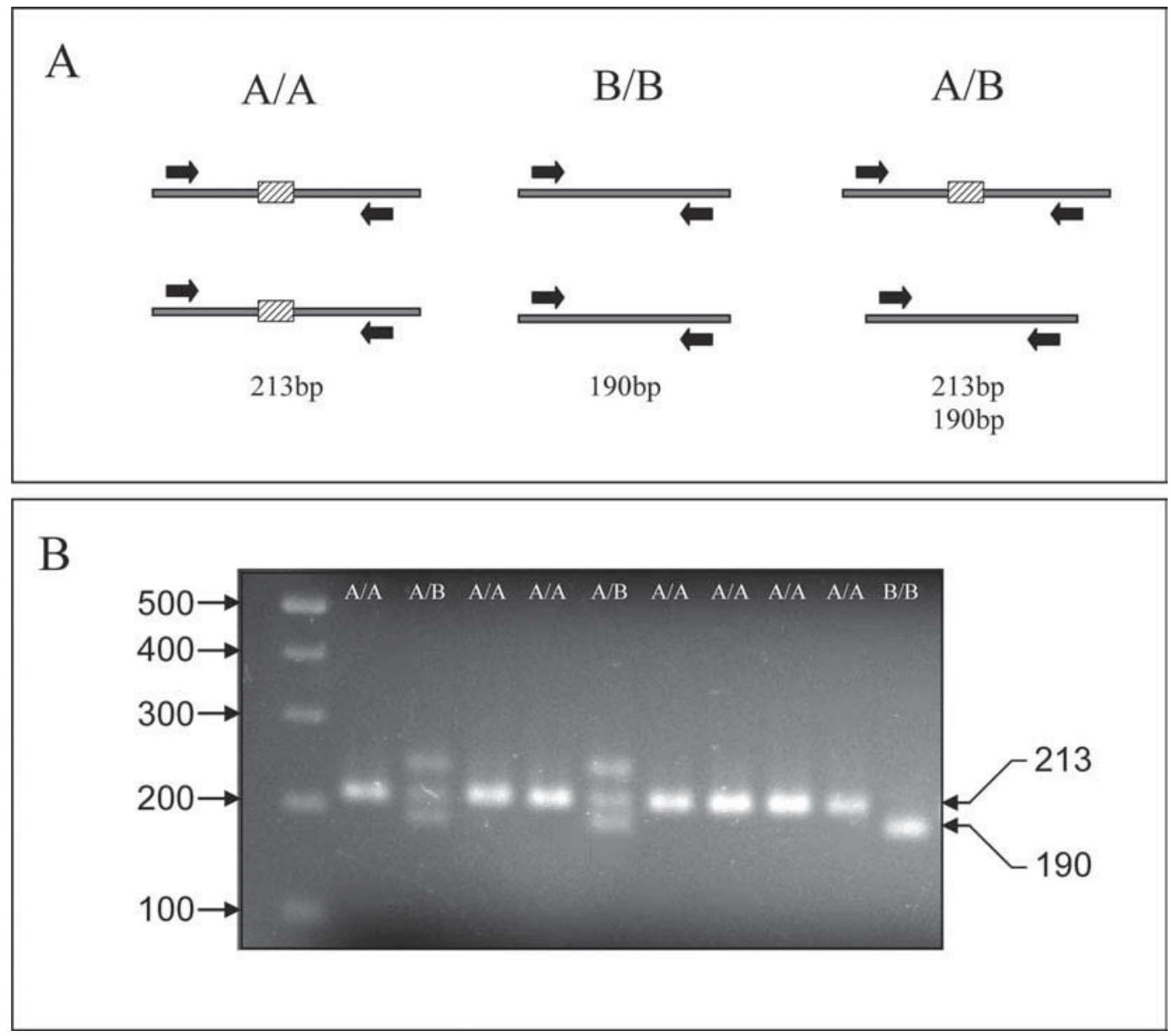

Figure 2. Analytical protocol for the detection of prolactin variants A and B. (A) Schematic representation and rational behind the method; (B) agarose gel demonstrating a genotyping experiment of 10 Chios sheep showing all 3 genotypes.

(1997) that included amplification of the 1,209- or 1,186-bp PCR fragment and subsequent digestion with HaeIII. The modified version was preferred to the original method because it was often difficult to obtain the 2.5-kb fragment from a large number of samples.

For the modified PCR-RFLP assay, PCR reactions were set up in a final volume of $25 \mu \mathrm{L}$ using $25 \mathrm{ng}$ of genomic DNA, $1.5 \mathrm{mM} \mathrm{MgCl} 2,0.4 \mu M$ PRL-F (5'-ACCTCTCCTCGGAAATGTTCA-3'), $0.4 \mu M$ PRL-R (5'-GGGACACTGAAGGACCAGAA-3'), and $1 \mathrm{U}$ of Taq DNA polymerase (Qiagen). Following an initial 5 -min denaturation step at $94^{\circ} \mathrm{C}$, the PCR reactions were subject to 30 cycles of $94^{\circ} \mathrm{C}$ for $30 \mathrm{~s}, 56^{\circ} \mathrm{C}$ for 30 $\mathrm{s}, 72^{\circ} \mathrm{C}$ for $60 \mathrm{~s}$, and a final elongation step for $5 \mathrm{~min}$ at $72^{\circ} \mathrm{C}$. For detection of the 2 variants, the 1,209 - or 1,186-bp fragments (A and $\mathrm{B}$ variants, respectively) were digested for $2 \mathrm{~h}$ at $37^{\circ} \mathrm{C}$ with $8 \mathrm{U}$ of HaeIII, and digestion products were resolved on $2 \%$ agarose gels. Expected fragment sizes were as follows: A variant, 540, 370, 147, and 152 bp; B variant, 517, 370, 147, and $152 \mathrm{bp}$.
The genotyping results obtained by the 2 assays were in complete agreement, findings that were also confirmed by sequencing of selected gel-purified PCR products from both methods. Single, clean PCR bands of the expected sizes were generated from $\mathrm{AA}$ and $\mathrm{BB}$ homozygous animals. However, when heterozygous animals were analyzed, in addition to the 2 alleles being successfully detected, an additional higher molecular weight band also appeared (Figure 2). The extra, larger band could not be eliminated by altering the PCR conditions in any way, not even by the use of a touch-down technique, nor by designing other sets of primer pairs within the intron. Nevertheless, its presence did not affect in any way the correct genotyping of heterozygous animals. Sequencing of this band indicated that it comprised mixed signals generated from both alleles, possibly due to the formation of heteroduplexes because of a loop structure in the area of deletion (Triggs-Raine and Gravel, 1990; Romey et al., 1993; Harada et al., 1995).

To further evaluate the PCR assay, 356 Chios sheep were successfully genotyped with the future aim of 
identifying any possible associations with milk traits. All Chios sheep were part of the experimental flock held at the Agricultural Research Institute and could be considered unrelated based on low inbreeding estimates (C. Brown, Cyprus University of Technology, Lemesos, Cyprus, and A. Mavrogenis, Agricultural Research Institute, Lefkosia, Cyprus, personal communication). Allelic frequencies in the initial sample set of 40 Chios sheep did not vary significantly from those obtained from the entire genotyped dataset of 356 animals (A: 0.74 vs. 0.72 ; B: 0.26 vs. 0.29 for the 40 and 356 sample sets, respectively), whereas allelic and genotyping frequencies between the 2 breeds were significantly different $(P<0.01)$. In particular, the frequency of the $\mathrm{B}$ allele carrying the deletion was 0.29 in Chios sheep, but 0.09 in Cyprus Fat-Tailed sheep. Nine percent of Chios sheep were homozygous for the deletion and $39 \%$ were heterozygous, whereas no homozygotes for the deletion were detected in the 40 Cyprus Fat-Tailed sheep, of which $17.5 \%$ were heterozygous. It has been reported that Cyprus Fat-Tailed sheep produce almost half the milk (average of $107 \mathrm{~kg}$ /lactation) the Chios breed (average of $222 \mathrm{~kg} /$ lactation) produces, but with a much higher fat content $(7.6 \%$ vs. $6.5 \%$ in Chios sheep; http://dad.fao.org/). Therefore, it could be speculated that the B allele carrying the deletion may be associated with higher milk yield, as also suggested by Ramos et al. (2009). However, association studies examining individual animal milk production data from both breeds farmed under the same management and nutritional conditions are required to investigate and confirm any putative correlations.

Moreover, although intronic deletions are common features in mammalian genomes, it is well documented that intronic regulatory elements function as enhancers, repressors, and promoters of gene transcription (Busch et al., 1999). In addition, in many cases, deletions in introns have been found to affect gene expression and susceptibility to diseases in humans (Ichikawa et al., 2006; Parle-McDermott et al., 2007; Cam et al., 2009). Taking into consideration the importance of the $P R L$ gene in milk secretion (Knight, 2001), and its location in a region where putative QTL for milk traits have been identified (Barillet et al., 2005; Gutiérrez-Gil et al., 2009), the $P R L$ intronic polymorphism caused by this deletion merits further investigation. To confirm whether the PRL A and B variants affect milk yield or composition, a large number of individuals from different breeds should be tested before inclusion of any advantageous allele in marker-assisted selection programs. To facilitate these high-throughput screening studies, the availability of a rapid, reliable, and cost-effective analytical protocol would be highly advantageous. The simplified PCR assay presented here provides such a method for large-scale genotyping of the variants in $P R L$ intron 2.

\section{ACKNOWLEDGMENTS}

This work was supported by the Cyprus Research Promotion Foundation (Lefkosia, Cyprus) and the Cyprus University of Technology (Lemesos, Cyprus).

\section{REFERENCES}

Barillet, F., J. J. Arranz, and A. Carta. 2005. Mapping quantitative trait loci for milk production and genetic polymorphisms of milk proteins in dairy sheep. Genet. Sel. Evol. 37(Suppl. 1):S109 S123.

Busch, M. A., K. Bomblies, and D. Weigel. 1999. Activation of a floral homeotic gene in Arabidopsis. Science 285:585-587.

Cam, R., A. Eroglu, Y. Egin, and N. Akar. 2009. Dihydrofolate reductase (DHRF) 19-bp intron-1 deletion and methylenetetrahydrofolate reductase (MTHFR) C677T polymorphisms in breast cancer. Breast Cancer Res. Treat. 115:431-432.

Carta, A., S. Casu, and S. Salaris. 2009. Invited review: Current state of genetic improvement in dairy sheep. J. Dairy Sci. 92:58145833.

Gutiérrez-Gil, B., M. F. El-Zarei, L. Alvarez, Y. Bayón, L. F. de la Fuente, F. San Primitivo, and J. J. Arranz. 2009. Quantitative trait loci underlying milk production traits in sheep. Anim. Genet. 40:423-434.

Harada, S., S. Fukuda, H. Tanaka, Y. Ishiguro, and T. Sato. 1995. Genetic analysis of the trait of sucrose accumulation in tomato fruit using molecular marker. Breed. Sci. 45:429-434.

Ichikawa, S., A. H. Sorenson, E. A. Imel, N. E. Friedman, J. M. Gertner, and M. J. Econs. 2006. Intronic deletions in the SLC34A3 gene cause hereditary hypophosphatemic rickets with hypercalciuria. J. Clin. Endocrinol. Metab. 91:4022-4027.

Knight, C. H. 2001. Overview of prolactin's role in farm animal lactation. Livest. Prod. Sci. 70:87-93.

Parle-McDermott, A., F. Pangilinan, J. L. Mills, P. N. Kirke, E. R. Gibney, J. Troendle, V. B. O'Leary, A. M. Molloy, M. Conley, J. M. Scott, and L. C. Brody. 2007. The 19-bp deletion polymorphism in intron-1 of dihydrofolate reductase (DHFR) may decrease rather than increase risk for spina bifida in the Irish population. Am. J. Med. Genet. A. 143A:1174-1180.

Ramos, A. M., C. A. P. Matos, P. A. Russo-Almeida, C. M. V. Bettencourt, J. Matos, A. Martins, C. Pinheiro, and T. Rangel-Figueiredo. 2009. Candidate genes for milk production traits in Portuguese dairy sheep. Small Rumin. Res. 82:117-121.

Romey, M. C., P. A. Martinez, J. Demaille, and M. Claustres. 1993. Rapid detection of single nucleotide deletions: Application to the 136 (-A) mutation of the -globin gene and to cystic fibrosis. Hum. Genet. 92:627-628.

Schwarz, K., T. Hansen-Hagge, and C. Bartram. 1990. Improved yields of long PCR products using gene 32 protein. Nucleic Acids Res. 18:1079.

Staiger, E. A., M. L. Thonney, J. W. Buchanan, E. R. Rogers, P. A. Oltenacu, and R. G. Mateescu. 2010. Effect of prolactin, betalactoglobulin, and kappa-casein genotype on milk yield in East Friesian sheep. J. Dairy Sci. 93:1736-1742.

Triggs-Raine, B. L., and R. A. Gravel. 1990. Diagnostic heteroduplexes: Simple detection of carriers of a 4-bp insertion mutation in Tay-Sachs disease. Am. J. Hum. Genet. 46:183-184.

Vincent, A. L., and M. F. Rothschild. 1997. Rapid communication: A restriction fragment length polymorphism in the ovine prolactin gene. J. Anim. Sci. 75:1686.

Wilton, S., and L. Lim. 1996. Long-range PCR: Synthesis of products independent of size. Trends Genet. 12:458. 